\title{
OSTEOID OSTEOMA OF THE SKULL
}

\author{
B. Prabhakar, D. Raja Reddy, B. Dayananda and G. Raghava Rao, \\ HYDERABAD, INDIA
}

From the Departments of Pathology, Medicine and Neurosurgery, Institute of Medical Sciences, Osmania Medical College, Hyderabad

Osteoid osteoma was first described as a distinctive benign osteoblastic tumour by Jaffe (1935). Lichtenstein (1965) defined osteoid osteoma as a small, oval or roundish tumour-like nidus composed of osteoid and trabeculae of newly formed bone deposited within a substratum of highly vascularised osteogenic connective tissue.

This lesion has been reported in almost every bone but not previously in the skull (Jaffe 1958, Lichtenstein 1965, Sutton 1969).

\section{CASE REPORT}

A male medical student aged twenty-one was admitted to the Osmania General Hospital in August 1970 with persistent pain in the left frontal region of the skull for eighteen months. The pain had gradually become localised to a small area behind the hair line in the left frontal

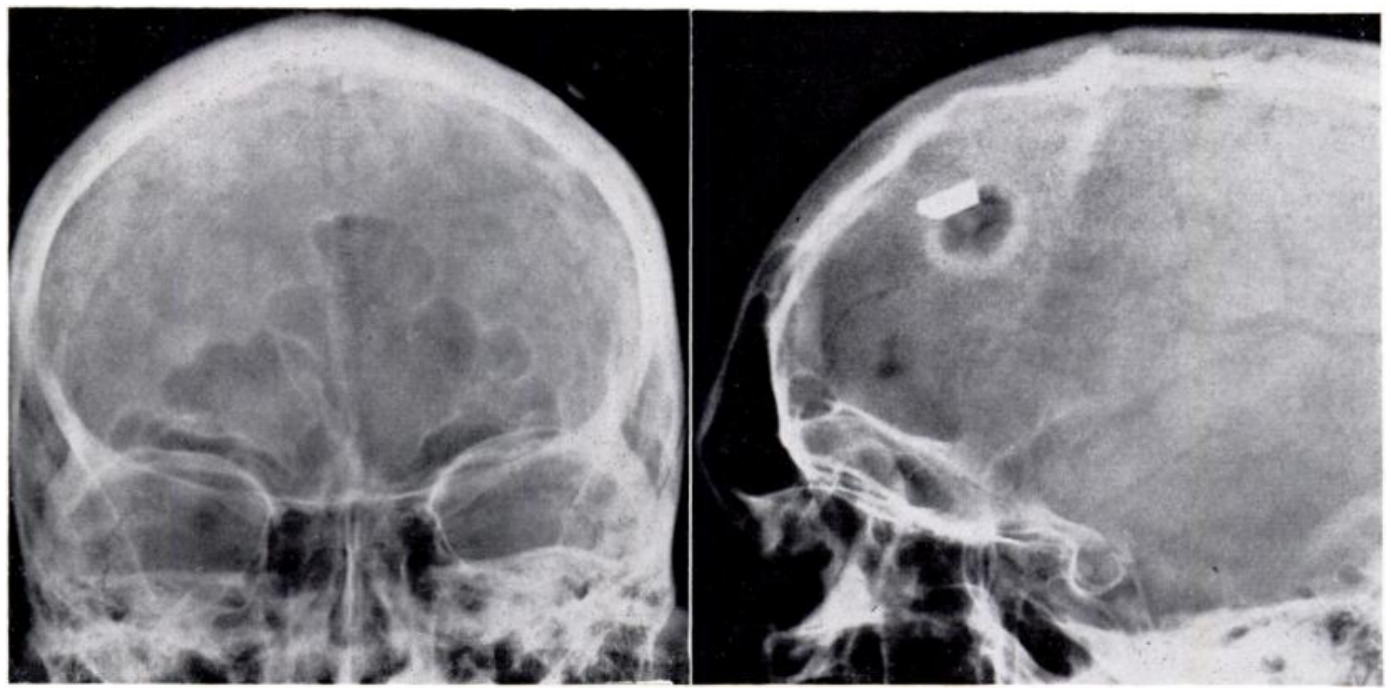

FIG. 1

FIG. 2

Figure 1-Antero-posterior view of the skull showing the defect. Figure 2-Lateral view of the skull with the area of tenderness indicated by a metal marker. Note the central dense round shadow.

region. It was a continuous pain, "boring" in character, and worse at night. At first analgesics had relieved the pain, but later, relief was only partial. The pain had been so severe that the patient became intensely irritable and aggressive; in consequence, he attended the psychiatric department where he was treated for some time with electro-convulsive therapy. Since the pain persisted, he sought advice from one of us (G. R. R.) and in view of the unusual findings in the skull he was referred to the neurosurgery unit.

On examination he was otherwise healthy, but clearly much worried about his ailment. There was localised tenderness behind the hair line in the left frontal region but on palpation there was no evidence of a swelling or erosion of the bone. 
Investigations-Complete blood picture, urine analysis, erythrocyte sedimentation rate and chest radiograph were normal. Plain radiographs of the skull revealed an area of rarefaction with sclerosed margins in the left frontal region corresponding to the area of tenderness (Figs. 1 and 2). There was a small central area of increased density.

Operation-A concealed scalp flap centred on the skull defect was turned. Separation of the periosteum revealed a thin outer table over a defect measuring $1 \times 1.5$ centimetres. The

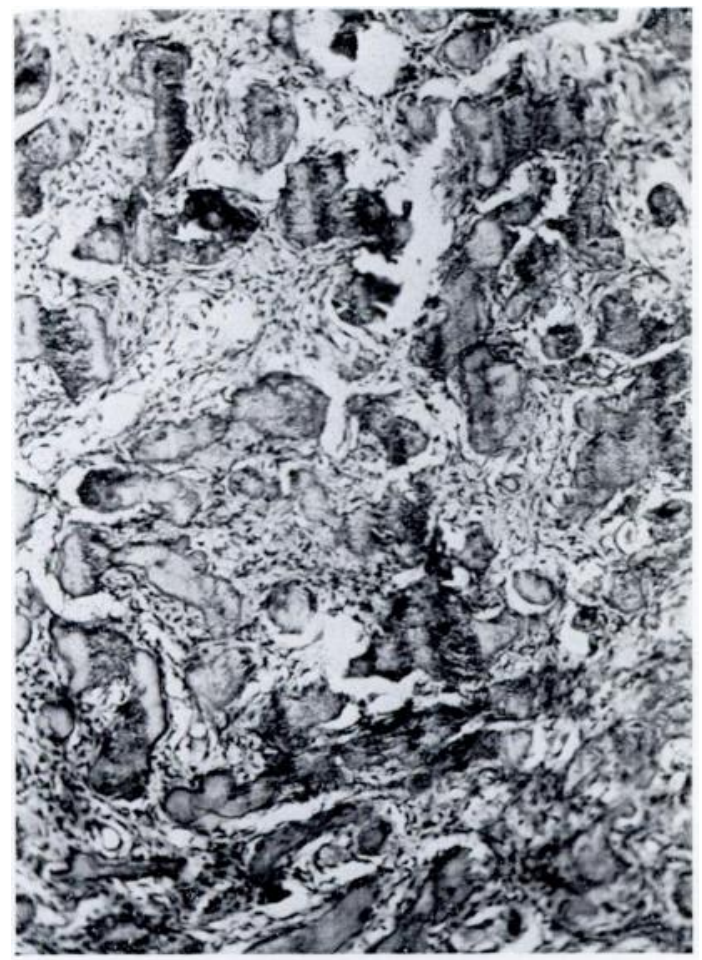

Fig. 3

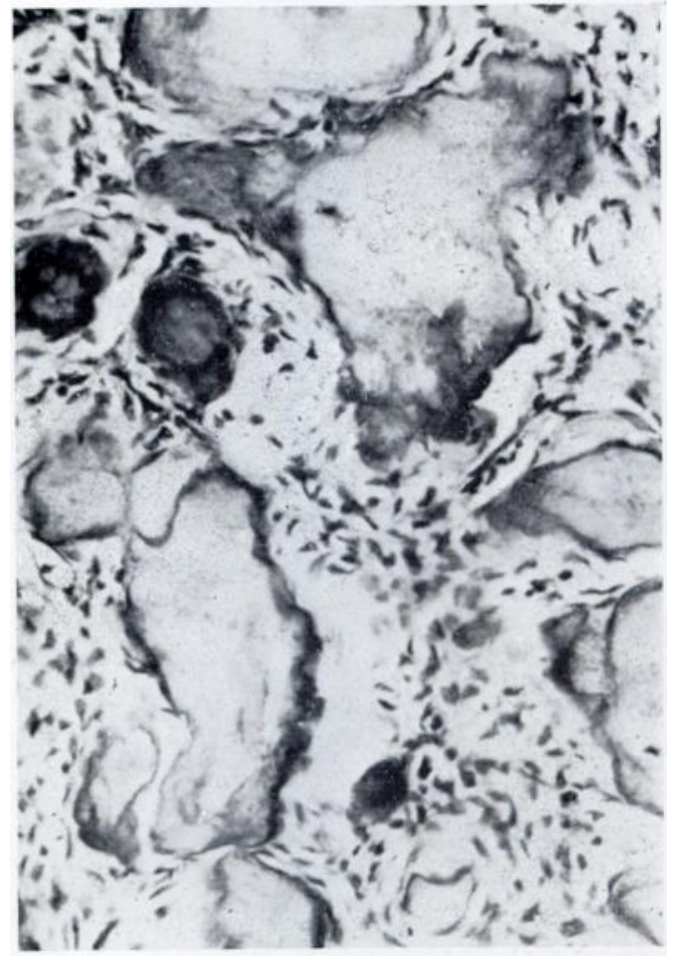

Fig. 4

Figure 3-The atypical bone trabeculae in a connective tissue substratum. (Haematoxylin and eosin, $\times 60$.) Figure 4-Osteoblasts rimming the bone trabeculae. (Haematoxylin and eosin, $\times 200$.)

cavity was filled by brownish red material. In the centre was a nidus of bone 0.5 centimetre long. The sclerotic margins of the defect were widely excised. The inner table of the skull was found to be intact. Radiographs of the fragment of bone confirmed the presence of calcium.

Pathology - The central nidus of the specimen (the osteoid osteoma proper) was a small, oval, rounded, circumscribed, reddish mass about 0.5 centimetre diameter. The surrounding bone was thickened.

In stained sections the nidus was composed of osteoid tissue and trabeculae of irregularly formed bone. The bone was calcified to a greater extent peripherally than in the central part (Fig. 3). The bone trabeculae were rimmed by osteoblasts (Fig. 4). A connective tissue substratum could also be made out. Under polarised light the bone revealed a lamellar pattern (Fig. 5). The surrounding bone showed sclerosis.

Progress-After the operation the patient was relieved of pain.

\section{DISCUSSION}

The lesion was typical of osteoid osteoma and the histological appearances confirmed this. Benign osteoblastoma and fibrous dysplasia were alternative possibilities, but since the 
trabeculae of new bone were rimmed by osteoblasts, the latter was ruled out. Moreover, under polarised light the lesion showed a lamellar pattern which is not seen in uncomplicated fibrous dysplasia (Reed 1963). Histologically some of the benign osteoblastomas and osteoid osteomas resemble each other very closely. But benign osteoblastomas are larger and not sharply defined with ovoid or spherical contours as obtained in this case.

Apart from the histological findings, the diagnosis of osteoid osteoma should be supported by clinical and radiological evidence. The clinical picture in the present case was very suggestive

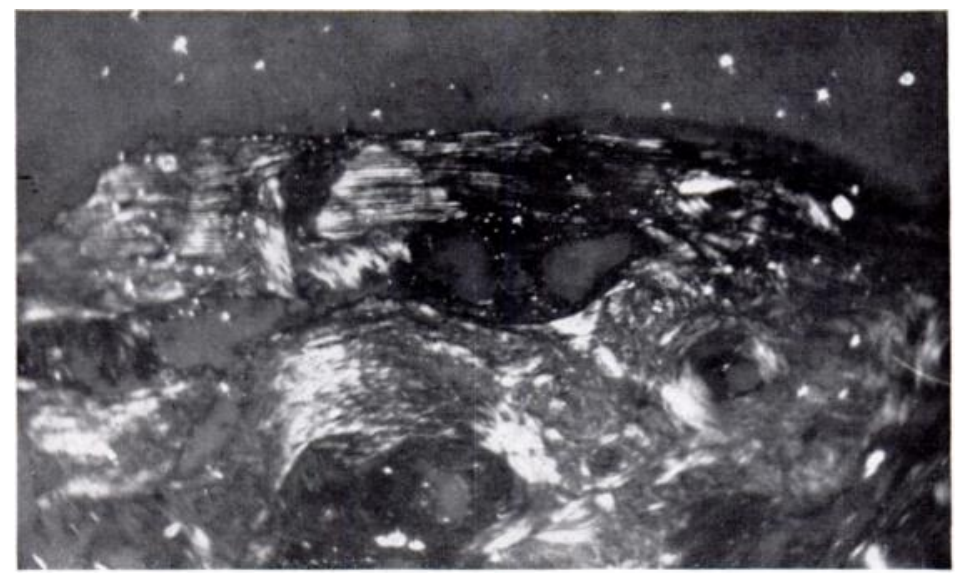

FIG. 5

Appearance under polarised light. Note the lamellar pattern.

of osteoid osteoma except for the site of the lesion. Localised pain in osteoid osteoma is reported as so severe that in the absence of an obvious organic basis, such patients have been referred to the psychiatrist. This happened in the present case. Indeed, the onset of pain may precede the radiological appearances so typical of the lesion. Exquisite local tenderness is also a striking feature. Such pain or tenderness is not encountered in osteoblastoma.

Radiologically the presence of the central nidus surrounded by dense sclerosis was characteristic of the lesion. The sclerosis of surrounding bone is the essential feature without which Lichtenstein (1965) would not designate a lesion as osteoid osteoma.

\section{SUMMARY}

1. A case of osteoid osteoma of the skull is reported, with characteristic clinical, radiological and pathological features.

2. Osteoid osteoma of the skull has not previously been reported.

\section{REFERENCES}

JAFFE, H. L. (1935): “Osteoid-osteoma." Archives of Surgery, 31, 709.

JAFF, H. L. (1958): Osteoid-osteoma. In Tumors and Tumorous Conditions of the Bones and Joints, p. 92. Philadelphia: Lea \& Febiger.

Lichtenstein, L. (1965): Osteoid-osteoma. In Bone Tumors. Third edition, p. 90. St Louis: The C. V. Mosby Company.

ReEd, R. J. (1963): Fibrous Dysplasia of Bone. Archives of Pathology, 75, 480.

Sutron, D. (1969): Osteoid Osteoma. In A Textbook of Radiology, p. 87. Edinburgh and London: E. \& S. Livingstone Ltd. 